\title{
Promoting the Conduct of Medical Education Journal Clubs in Teaching Medical Institutions
}

\author{
Saurabh R. Shrivastava ${ }^{1, \odot} \quad$ Prateek S. Shrivastava ${ }^{1, \oplus}$ \\ 1 Department of Community Medicine, Shri Sathya Sai Medical \\ College and Research Institute, Sri Balaji Vidyapeeth, Deemed-to- \\ be University, Nellikuppam, Chengalpet District, Tamil Nadu, India
}

Avicenna J. Med. 2021;3:156-159.

\begin{abstract}
Address for correspondence Saurabh R. Shrivastava, MBBS, MD, Saurabh R. Shrivastava, MBBS, MD, Medical Education Unit Coordinator, Member of the Institute Research Council, Department of Community Medicine, Shri Sathya Sai Medical College and Research Institute, Sri Balaji Vidyapeeth, Deemed-to-be University, Nellikuppam, Chengalpet District 603108, Tamil Nadu, India. (e-mail: drshrishri2008@gmail.com).
\end{abstract}

\begin{abstract}
Keywords

- journal club

- critical appraisal

- medical education

Background A critical appraisal of a research article as a part of journal club sessions is an essential aspect of postgraduate training across different medical institutions in varied settings. The purpose of the current review was to explore the merits of medical education journal clubs and identify the potential factors that need to be considered for conducting these journal clubs in medical institutions.

Methods An extensive search of all materials related to the topic was performed in the PubMed search engine and a total of 51 studies were included in the review based on the suitability with the current review objectives. Keywords used in the search include medical education journal clubs in the title only (viz., journal club [ti] AND medical education [ti]; medical education journal clubs [ti]; journal club [ti]). The articles published in English language only were included in the review.

Results Regardless of the extensive employment of the journal clubs in different medical specialties, it is quite alarming to note that not many institutions conduct journal clubs targeting the field of medical education. These sessions offer a unique opportunity to the participants to assess the literature in a supportive fashion and play a defining role in ensuring better quality health care teachings to the medical students. However, we must understand that the successful conduct of medical education journal clubs requires specific considerations and groundwork, so that the students may benefit.

Conclusion In conclusion, the medical education journal clubs have not been frequently conducted, as more preference has been given to the subject-specialty journal clubs. However, considering the scope and benefits that journal clubs add to improve teaching, all medical institutions should advocate to conduct medical education journal clubs within their premises in a structured manner.
\end{abstract}

\section{Introduction}

A critical appraisal of a research article as a part of journal club sessions is an essential aspect of postgraduate

published online August 31, 2021
DOI https://doi.org/

$10.1055 / \mathrm{s}-0041-1735126$

ISSN 2231-0770 training across different medical institutions in varied settings. ${ }^{1,2}$ These journal club sessions play a significant role in not only exposing the students to recent advances but also to the research methodology and skills of critical appraisal

(c) 2021. Syrian American Medical Society.

This is an open access article published by Thieme under the terms of the Creative Commons Attribution-NonDerivative-NonCommercial-License, permitting copying and reproduction so long as the original work is given appropriate credit. Contents may not be used for commercial purposes, or adapted, remixed, transformed or built upon. (https://creativecommons.org/licenses/by-nc-nd/4.0/).

Thieme Medical and Scientific Publishers Private Limited A-12, Second Floor, Sector -2, Noida-201301, Uttar Pradesh 
which are essential to decide the validity of the study findings. ${ }^{3-7}$ We should also remember that these journal club sessions promote active learning through discussions, build self-directed learning platform for students, aid them to develop leadership qualities, and even guide them toward practicing evidence-based medicine which is an essential prerequisite in clinical practice in the modern era. ${ }^{8-13}$ The purpose of the current review was to explore the merits of medical education journal clubs and identify the potential factors that need to be considered for conducting the same in medical institutions.

\section{Methods}

An extensive search of all materials related to the topic "medical education journal club" was performed in the PubMed search engine. Relevant research articles focusing on the topic published between 2001 and 2020 were included in the review. A total of 59 studies were identified initially of which 8 were excluded due to the nonavailability of full-text article. Eventually, 51 research articles were included in the review based on the suitability with the current review objectives. Keywords used in the search include medical education journal clubs in the title only (viz., journal club [ti] AND medical education [ti]; medical education journal clubs [ti]; journal club [ti]). The articles published English language only were included in the review. The collected information from those searched articles is presented hereinafter under several headings..

\section{Journal Clubs}

A journal club refers to a type of an educational meeting where a group of individuals discuss and critique published articles and are being predominantly employed as an integral component of postgraduate training. ${ }^{1,14-17}$ This act of discussion and critique not only enables them to utilize findings of research in their practice but also acts as one of the modalities for the members to be aware of the recent developments in their fields of interest and research methodology. ${ }^{15-17}$ As students have to prepare for participating in different sessions, the journal clubs provide them an opportunity to become self-directed and life-long learners, as well as play a crucial role in enhancing their inclination toward practicing in evidence-based medicine. ${ }^{18-20}$ These journal clubs are conducted under the guidance of teachers or guides, and the students are the ones who make presentations to critique journal articles in the presence of other postgraduate students and department faculty members. ${ }^{21,22}$

\section{Reforms in the Journal Club}

There is a significant need to revamp the journal clubs in the training period to ensure that the students actively participate in the discussion and derive the benefits of the session. ${ }^{23-25}$ In fact, with time, different innovations should be introduced to conduct medical education journal clubs..$^{26-43}$ For instance, interactive journal clubs have been organized to enable better student involvement. ${ }^{26}$ At the same time, to neutralize the barrier of geographical locations, virtual and online journal clubs have been organized in heterogeneous settings. ${ }^{27-32}$ These virtual journal clubs cam be an ideal platform for the students to engage in quality discussion and facilitate team-based learning. ${ }^{30-35}$

Acknowledging the widespread use of social media among the youth, including medical students, the use of various social media platforms has been advocated and employed. ${ }^{36-38}$ The Twitter platform has been extensively used to conduct journal clubs in different streams and encouraging feedbacks from the participants have been obtained. ${ }^{37-41}$ Another study highlighted an innovative "flipped journal club" conducted in their settings to accomplish better attainment of learning outcomes. ${ }^{42}$ Before the actual session, students were given topics to do thorough preparation for a detailed discussion, while during the journal club, students were divided into small groups for discussion under the guidance of a teacher. This was followed by a discussion among all in a large group wherein everyone summarized the key findings. ${ }^{42}$ On a similar note, the journal clubs have also been organized using the podcast and the wiki platforms to reach a wider segment. ${ }^{43,44}$

\section{Medical Education Journal Clubs}

Regardless of the extensive employment of the journal clubs in different medical specialties, it is quite alarming to note that not many institutions conduct journal clubs targeting medical education. ${ }^{45,46}$ The medical education journal club refers to an evidence-based approach that makes it easy for both teacher/guide and student to teach and learn the critical appraisal techniques in the field. ${ }^{45}$ These sessions offer a unique opportunity to the participants to assess the literature in a supportive fashion which in turn empowers them to use the learned skills in the research domain. Further, these specific journal club sessions play a defining role in ensuring better quality health care teachings to the medical students. ${ }^{45-47}$

\section{Merits of Medical Education Journal Clubs}

The medical education journal clubs have been linked with several benefits as depicted in two of the research findings. ${ }^{45-51}$ In a study done in King Saud University, it was reported that medical education journal clubs are accounted for better knowledge acquisition in the field and had a positive impact on the expectations of the trainee students. ${ }^{48}$ On a similar note, a study done in Mexico revealed that the students who participated in the medical education journal clubs reported better skills in critical appraisal and the use of available evidence in the educational practice. ${ }^{49}$

\section{Smooth Conduct of Medical Education Journal Clubs}

However, we must understand that the successful conduct of medical education journal clubs requires specific considerations and groundwork, so that the students may 
benefit. ${ }^{1,45}$ The first and foremost thing is to decide how these planned medical education journal clubs can be useful to the students, and to make the journal clubs fruitful, it will be wise to select faculty members and postgraduate medical students for the same. ${ }^{46,47}$ This has to be followed-up by setting the objectives (viz., what we expect the students to learn at the end of such session), and this can range from making them aware about health sciences education literature, recent developments, promotion of educational research, facilitate discussion and debate, and teaching critical appraisal or research skills. ${ }^{46,50}$

Subsequently, the decision has to be taken about the periodicity of such sessions, and based on the feasibility, it can be either once in a month or a quarter, so that students are not overburdened. As such sessions are not limited to one specific department, it will be a welcome move to invite different stakeholders (such as faculty members, medical education unit members, postgraduate students from other departments, and others). ${ }^{46,51}$ It is always nice to ensure that different participants take lead for the conduct of the medical education journal club sessions, preferably in rotation, so that everyone remains involved in the process. ${ }^{1,46,47}$

As the number of such sessions conducted over a year is not many, it is quite essential that the article selected for the journal club session is novel, adds knowledge, and appeals interesting to all the participants. ${ }^{46,51}$ The selected articles should be shared with the participants to ensure that everyone comes well prepared for the journal club session and participates actively in the discussion. ${ }^{22}$ During the session, each of the present member critically appraises the article and highlights the important aspects of the publication. ${ }^{46,47,51}$

The session should end with a conclusion and the leader should summarize all the key findings. Finally, to sustain the benefits of medical education journal clubs, it is wise to periodically evaluate the initiative by obtaining feedback from the participants. ${ }^{47-49}$ In fact, appropriate modifications can be made in the planning and conduct of the journal club sessions based on the received feedback from different stakeholders. ${ }^{23-25}$ However, the overall success depends on the speaker and the interest shown by the attending participants. ${ }^{48-51}$

\section{Implications for Practice}

Medical education journal lubs possess immense potential to improve knowledge and skills of participating members by providing an understanding in topics of health science teaching. To ensure that these sessions are organized fruitfully, the medical education unit of an institution can take the lead. The members of the medical education unit can organize a sensitization program for all the faculty members and postgraduate students in batches. In addition, strict adherence to the above-mentioned tips can be ensured, so that the sessions remain interactive and beneficial. Further, some of the members of the medical education unit can be present for all such medical education journal clubs to help the other participants understand the concepts through their inputs.

\section{Implications for Research}

It is quite clear that medical education journal clubs are still in the initial stages in the current era of undergraduate or postgraduate teaching. This definitely creates a huge scope for research for its better introduction and implementation. The research activities can aim to identify the strengths and weaknesses of the medical education journal clubs and the role these journal clubs play in better understanding concepts. A qualitative or mixed methods study design can be employed to ascertain the merits of the medical education journal clubs and to identify the potential plan for its smooth introduction among the medical students.

\section{Strengths and Limitations of the Review}

The strength of the review is that not many such review articles are available that have focused on the theme of medical education journal clubs. The limitation of the review is that very few articles were enrolled in the review and thus we cannot generalize the review findings.

\section{Conclusion}

In conclusion, the medical education journal clubs have not been frequently conducted in the medical institutions, as more preference has been given to the subject-specialty journal clubs. However, considering the scope and the benefits that the journal clubs add to improve health science teaching, including facilitation of critical appraisal skills, all medical institutions should advocate to conduct such journal clubs within their premises in a structured manner.

\section{Conflict of Interest}

None declared.

\section{References}

1 Bhattacharya S. Journal club and post-graduate medical education. Indian J Plast Surg 2017;50(3):302-305

2 Ebbert JO, Montori VM, Schultz HJ. The journal club in postgraduate medical education: a systematic review. Med Teach $2001 ; 23(5): 455-461$

3 Malay DS. An effective journal club is important. J Foot Ankle Surg 2018;57(3):435

4 Garg T, Shrigiriwar A. Radiology journal club for medical students. Acad Radiol 2020;27(4):599

5 Deenadayalan Y, Grimmer-Somers K, Prior M, Kumar S. How to run an effective journal club: a systematic review. J Eval Clin Pract 2008;14(5):898-911

6 Burris JN, Frederick EK, Malcom DR, Raake S, Shin M, Daugherty KK. Impact of a journal club elective course on student learning measures. Am J Pharm Educ 2019;83(7):6827

7 Rodriguez J, Nyante SJ, Henderson L. Smith JK, Beck Dallaghan GL, Jordan SG. Radiology resident journal club: enhancements add educational value. Acad Radiol 2020;27(4):591-595

8 Feghali-Bostwick C, Harvey J, Hasseler C, Lee-Chavarria D, Halushka P. A team-based translational journal club: understanding the translational research highway. J Clin Transl Sci 2019;3(6):291-294 
9 Kattan JA, Apostolou A, Al-Samarrai T, et al. Beyond content: leadership development through a journal club. Am J Prev Med 2014;47(5(suppl 3):S301-S305

10 Mohr NM, Stoltze AJ, Harland KK, Van Heukelom JN, Hogrefe CP, Ahmed A. An evidence-based medicine curriculum implemented in journal club improves resident performance on the Fresno test. J Emerg Med 2015;48(2):222-229.e1

11 Milbrandt EB, Vincent JL. Evidence-based medicine journal club. Crit Care 2004;8(6):401-402

12 Ahmadi N, McKenzie ME, Maclean A, Brown CJ, Mastracci T, McLeod RS; Evidence-Based Reviews in Surgery Steering Group. Teaching evidence based medicine to surgery residents-is journal club the best format? A systematic review of the literature. J Surg Educ 2012;69(1):91-100

13 Stockler MR, March L, Lindley RI, Mellis C. ACP Journal Club. Students' PEARLS: successfully incorporating evidence-based medicine in medical students' clinical attachments. Ann Intern Med 2009;150(8):JC4-JC2, JC4-JC3

14 Baker JD. Journal Club as a resource for practice. AORN J 2013;98(2):102-106

15 Draganov PB, Silva MRG, Neves VR, Sanna MC. Journal club: a group of research experience. Rev Bras Enferm 2018;71(2):446-450

16 Mark I, Sonbol M, Abbasian C. Running a journal club in 2020: reflections and challenges. BJPsych Bull 2020;(e-pub ahead of print). doi:10.1192/bjb.2020.121

17 Singh A, Yogi P. Experience sharing: being a part of the journal club. JNMA J Nepal Med Assoc 2020;58(221):62-64

18 Dutta A, Ghosh S. Preparing and presenting journal club content: an essential component of homeopathic learning. Homeopathy 2020;109(4):261-266

19 Kawar E, Garcia-Sayan E, Baker-Genaw K, Drake S, Kaatz S. Journal club 102: enhancing evidence-based medicine learning using a virtual journal club. J Grad Med Educ 2012;4(1):116

20 Johnston AA, Holmquist S, Terplan M. Beyond the journal club: a decade of resident evidence-based medicine symposia at the University of Chicago. Med Teach 2010;32(4):347-348

21 Xiong L, Giese AK, Pasi M, Charidimou A, van Veluw S, Viswanathan A. How to organize a journal club for fellows and residents. Stroke 2018;49(9):e283-e285

22 Clauss JA, Cawkwell PB, Beach SR. Refreshing a resident-run journal club: a focus on article selection. Acad Psychiatry 2019;43(6):657-658

23 Cave MT, Clandinin DJ. Revisiting the journal club. Med Teach 2007;29(4):365-370

24 Al Achkar M. Redesigning journal club in residency. Adv Med Educ Pract 2016;7:317-320

25 Rodriguez RG, Hawley-Molloy JS. Revamping journal club for the millennial learner. J Grad Med Educ 2017;9(3):377-378

26 Rosenthal J, Rosenthal KS. Interactive journal club: teaching an old dog new tricks. J Med Educ Curric Dev 2017;4:2382120517719710, ; doi:10.1177/2382120517719710

27 Chan TM, Thoma B, Radecki R, et al. Ten steps for setting up an online journal club. J Contin Educ Health Prof 2015;35(2):148-154

28 Dundek C, Davis D, Thiers BH. Introducing the JAAD virtual journal club. J Am Acad Dermatol 2017;76(5):1009-1010

29 Touchet BK, Coon KA, Walker A. Journal Club 2.0: using team-based learning and online collaboration to engage learners. Acad Psychiatry 2013;37(6):442-443

30 Laranjeira C, Querido AI, Valentim O. Using an online journal club to improve evidence-based practice in mental health nursing students. J Nurs Educ 2020;59(12):723-724
31 Peacock A, Ward-Smith P, Elmore R. Providing an online nursing journal club and ensuring the rigor of the experience. Nurs Womens Health 2020;24(6):453-459

32 DuGan JE. "Keeping you in the know": the effect of an online nursing journal club on evidence-based knowledge among rural registered nurses. Comput Inform Nurs 2019;37(4):190-195

33 Musits AN, Mannix AL. Synchronous online journal club to connect subspecialty trainees across geographic barriers. West J Emerg Med 2020;21(1):33-36

34 Wray CM, Auerbach AD, Arora VM. The adoption of an online journal club to improve research dissemination and social media engagement among hospitalists. J Hosp Med 2018;13(11):764-769

35 Chetlen AL, Dell CM, Solberg AO, et al. Another time, another space: the evolution of the virtual journal club. Acad Radiol 2017;24(3):273-285

36 Leung E, Siassakos D, Khan KS. Journal club via social media: authors take note of the impact of \#BlueJC. BJOG 2015;122(8):1042-1044

37 Udani AD, Moyse D, Peery CA, Taekman JM. Twitter-augmented journal club: Educational engagement and experience so far. A A Case Rep 2016;6(8):253-256

38 Al-Imari L, Nutik M, Rozmovits L, Alvi R, Freeman R. Family medicine journal club: to tweet or not to tweet? Fam Med 2020;52(2):127-130

39 Topf JM, Sparks MA, Phelan PJ, et al. The evolution of the journal club: from Osler to Twitter. Am J Kidney Dis 2017;69(6):827-836

40 Garg T. Building a twitter journal club. J Am Coll Radiol 2019;16(8):1012

41 Currie G, Woznitza N, Bolderston A, et al. Twitter journal club in medical radiation science. J Med Imaging Radiat Sci 2017;48(1):83-89

42 Bounds R, Boone S. The flipped journal club. West J Emerg Med 2018;19(1):23-27

43 Banker SL, Motelow JE, LaRosa JM. Engaging paediatric residents through a journal club podcast. Med Educ 2020;54(11):1059-1060

44 Plante TB, Iberri DJ, Coderre EL. Building a modern journal club: the wiki journal club experience. J Grad Med Educ 2015;7(3):341-343

45 Pollart SM, Caelleigh AS. Changing conversations, changing culture: a medical education journal club. Med Educ 2011;45(11):1134

46 McLeod P, Steinert Y, Boudreau D, Snell L, Wiseman J. Twelve tips for conducting a medical education journal club. Med Teach 2010;32(5):368-370

47 Sherbino J, Joshi N, Lin M. JGME-ALiEM hot topics in medical education online journal club: an analysis of a virtual discussion about resident teachers. J Grad Med Educ 2015;7(3):437-444

48 Khan SA, Soliman MM. Medical education journal club: two years' experience at King Saud University. Pak J Med Sci 2017;33(5):1284-1287

49 Dzara K, Frey-Vogel AS. Medical education journal club for the millennial resident: An interactive, no-prep approach. Acad Pediatr 2019;19(6):603-607

50 Lin M, Joshi N, Hayes BD, Chan TM. Accelerating knowledge translation: Reflections from the online ALiEM-annals global emergency medicine journal club experience. Ann Emerg Med 2017;69(4):469-474

51 Sánchez-Mendiola M, Morales-Castillo D, Torruco-García U, Varela-Ruiz M. Eight years' experience with a medical education journal club in Mexico: a quasi-experimental one-group study. BMC Med Educ 2015;15:222 